\title{
How to Cultivate Positive Mental Attitude
}

\author{
Gong-luo Zhu ${ }^{1, a}$ and Wei Zeng ${ }^{2, b}$ \\ ${ }^{1}$ School of Humanities in Kunming University, Yunnan Kunming ,China 650214; \\ ${ }^{2}$ Yunnan National University affiliated primary school,Yunnan Kunming, China 650500; \\ a15969552293@163.com, bkmzengweigood@163.com
}

Keywords: positive mental attitude, Cultivate, Learning helplessness, Positive hints, Optimistic attitude.

Abstract. Positive mental attitude is very important to our life.There are some methods to cultivate the positive mentality ,such as establishing ideal, cultivating sense of responsibility, positive suggestion, cultivating toughness and keeping optimism.

\section{Introduction}

Positive attitude attitude (short for PMA)refers that the people facing to the difficult, dangerous, failure, frustration, misunderstanding and so on in his life, can always use positive thinking, optimistic spirit, high-spirited morale, full of enthusiasm to control their own domination, so as to constantly overcome difficulties, and continue to success." PMA is a kind of thought, behave ,or reflect which is correct, sincere and constructive approach to anyone, any situation or environment, without violating the laws and human rights.PMA means people consider both good side and bad side of something when they face it, but the emphasis is on the good side, then, it will produce good wishes and results. "[1] PMA is not a momentary whim, but a relatively stable psychological trend, with a strong psychological orientation.It can make people who face to difficulties show a consistent positive attitude, the more frustrated he faces, the more excited he is, and he keeps perseverance, and finally achieve success. Of course, "people have joys and sorrows, just like the moon has cloudy and clear round", to maintain PMA for ever may be very very difficult, but to maintain PMA for most of the time is still possible.At the very least, PMA can also make some unfortunate people have a hope, thereby adding to the courage and confidence of life.

\section{The importance of PMA}

PMA is very important to us. Napoleon Hill, one of the most famous successful scientists, who wrote a book "Creating Wealth" which was been seen as a masterpiece of "making a Politicians, creating a millionaire", after decades of exploration and research, summed up 17 golden laws of success, the first of which is PMA.[2]

From the practice point of view, the influence of PMA to the human is also heavy.Take an example for it.Former man soccer coach Milutinovic is a "magic coach".He led four different national teams into the World Cup finals and made a good record.He had a famous saying "attitude is everything",and,he put these words on the hat. Chinese men football team made a historic break to enter the World Cup finals in 2002 World Cup in Korea and Japan, it is inseparable to the thing that Milutinovic brought PMA to the players.

\section{How to cultivate PMA?}

PMA effect our life, our work and our study.There is only a small difference between people, and ultimately caused a huge difference between people, resulting in these differences is the mentality of people.PMA can change the world.So, how to cultivate our PMA? 


\subsection{Establish the ideal.}

Lincoln said that If a person is determined to achieve some kind of happiness, he can get this kind of happiness, which shows the great effect of ideal.Ideal is like a lighthouse which guides the ship successfully to reach the other side.An ideal man always tries hard to overcome all the difficulties he meets until he realizes the ideal.In the process of achieving the ideal, people constantly break through,and keep close to the goal, and the ideal is like a giant magnet, which can hold on to the people who struggle for it.If a person does not have an ideal, there is no clear goal, he will do nothing, accomplish nothing, it can say, ideal conceives PMA .It is impossible to have PMA without an ideal person.

\subsection{Cultivate a sense of responsibility.}

A sense of responsibility is also an important factor that affects a positive mindset. When a person feels that he is responsible for doing something, if he does not do it, he will be condemned to his conscience, thus creating a strong self-discipline, we can say that he has a sense of responsibility.

The strength of responsibility is directly proportional to the size of self-binding. The people, who has strong self-binding ,has a strong ability to control his/her own heart, and can insist on a certain way of doing things and the code of conduct in specific behavior.Responsibility includes two aspects: one, have the responsibility to do something;two, Be responsible for what you do.The former urges people to actively and consciously engage in meaningful things, rather than passively and attached to do what they do not know clearly. The latter can lead the perpetrator to take the consequences positively, and the prior consideration of the possible consequences of the event can be a guide to the behavior of the perpetrator,just like Confucius said that you should think over before done.A person feels that he has the responsibility to do something, and do it actively, it is just the performance of PMA, so that the cultivation of responsibility is also in the cultivation of PMA.

\subsection{Positive self-implication}

Positive self-hinting is also an effective way to develop PMA. The positive self-hinting has many kinds of performance, one can be called self-motivation, such as yelling at yourself every day in the mirror: "I'm awesome!" "that’s great!” "I'll do it!" ”, "I will succeed!" ”, "Today will be a beautiful day!",and so on.

There is also a positive psychological hint, called Drawing in the Brain, which can also be called positive imagination. For example, a person who was getting ready for postgraduate examination, he thought in the mind of such a picture: After he passed the postgraduate examination, the family held a feast, came a lot of guests, everyone tried to praise him;He became the pride of their family, but also the pride of the villagers ... At last, of course, the man succeeded.The suggestive effect of this positive imagination is very large.

\subsection{Believe in self and drive away your inferiority}

PMA can be divided into two dimensions:internal and external, or self and external things .In the internal dimension, PMA means someone is confidence and feels satisfied with himself /herself.In the external dimension, PMA means someone often looks for the hope and takes measures to achieve it, even when encountering difficulties, obstacles and disadvantages.Believe in self and drive away your inferiority is the internal training program for PMA.

In life, people inevitably suffer from failure, frustration,or some hit else, in this case, the weak will easily form the inferiority mind, "I am so stupid!" "I am really worse than them." The ultimate of inferiority is Learned Helplessness.It refers to such a situation: After repeated failures, someone no longer ascribes failure to bad luck or task is too difficult, but the failure attributed to their own ability, it will produce a sense of incompetence, helplessness, in this sense, they do not want to learn, do not want to try again, causing a vicious circle of lower performance_-failure-lack of ability-sense of loss-worse performance.[3] 
Inferiority is the antithesis of positive mentality, so, drive up inferiority and build self-confidence is two aspects of the same process.So, how to dispel inferiority,and build self-confidence?

I think we can start with the following points:

1.Correct understanding of their own strengths and weaknesses, do not compare their own shortcomings with the advantages of others, that will let people feel inferiority;Also do not compare their own advantages with other people's shortcomings, in that people fall in vanity, vanity is most easily crushed by reality, in the end will only let people more inferiority.

2.Develop concrete and achievable goals, put into practice and achieve goals effectively.

3. Changing attribution tendencies, attributing failure to lack of effort, rather than lack of capacity, it will make somebody try his/her best to succeed.

4.Make a summary in time, compare today's me with yesterday's me, Compare me in now with what I used to be, to find the the harvest and success, affirm my own achievements.

5. Equal competition.To guide and encourage ourselves to compare and compete with those who have the same ability as ourselves, we should find out the gap and establish the direction of effort, and establish the belief that he can, I will be able to do it.

6. Follow the example.Choose the right object as an example of learning. As we grow older, our choice of example will have a tendency to transform from a concrete example to an abstract, spiritual example.In the process of learning example, we will achieve achievement in the similar way, will also be recognized by others, will achieve our own value, so that we will not be inferiority but full of self-confidence.

\subsection{Improve the capacity to withstand frustrations}

Frustration is a required course in life, but also a wealth of life.In the face of frustrations ,the weak-willed people will be deterred from being discouraged,and flinch, and often difficult to achieve big events.Only those who can withstand frustrations and pass the hard test,then have a strong and powerful wings, an infinitely bright future they will have.

The sage of our country Mencius once said: "God want assign great task to the person ,at first,God must bitter his mind, labor his bones and muscles, hungry for food , empty his body, disorder his life daily, so that make him move and restrain his desire,and inspire his potential. "The English poet Shelley also said: "If you cherish your feathers so much that it doesn't hurt a little, you will lose two wings and never be able to fly again." What the two men said tell us: Human must undergo setbacks in their growth, they should have resilience, and they can draw strength from the setbacks , finally will succeed.Zheng Banqiao's famous sentence praised the bamboo, "No matter the wind blows from East,South,West or North, and no matter the strong wind blows the bamboo thousands of times, the bamboo remains strong and upright", what the sentence advocate is also a tough spirit of defying difficulties. With higher frustration tolerance, it will form toughness.A tough person must have PMA, from this point of view, improve frustration tolerance, cultivate toughness, is to cultivate PMA.

\subsection{Keep an optimistic attitude.}

China's Song Dynasty poet Xin Qiji said "Sigh in life, not satisfactory things, often eight or nine in ten", everyone may have a lot of trouble and frustration in life, but all this will go, so we have to maintain an optimistic mentality, to believe that the future will be better.Optimism is the beacon of hope, which can make us move from danger to smooth road, so that our ideals will never be disillusioned.

Two people walking in the desert, each saw half a bottle of water.The optimistic people looked and said: "There is half a bottle of water, I can support for a long time."While, the pessimistic person looked and said: "Only half a bottle of water ah, I am dead!" It is not difficult to imagine that these two kinds of attitudes will have a very different impact on their fate. 


\section{In addition}

PMA is undoubtedly very important, it can make our life unpredictably change, it is an important magic weapon of success. A clear goal plus PMA is the starting point for all success.However, PMA also has a problem of extent.Let what will be will be, do not force,not go too far,just like Confucius once said "going too far is as bad as not going far enough".In addition, to maintain PMA, in fact, it presets a theoretical premise, that is, you think about, your ideals, your pursuit should be harmless to the society, not hinder morality and law, be not contrary to the public order and custom.If someone takes a positive attitude for evil, he lose the original meaning of PMA.

\section{References}

[1] Ailing Yuan, The center of the Family education--the cultivation of positive mentality [J]--Enlightenment(0-7years old), 2003 18(4):2-3.

[2] Napoleon Hill, Creating Wealth[M],Enterprise Management Press, 1997:1.

[3] Qi Chen, Rude Liu, Contemporary Educational psychology[M], Beijing Normal University Press, 2006:135. 